\title{
La última frase de Bolívar
}

\author{
José Luis Ayala \\ Estudios andinos desde la cosmopercepción \\ munasnawa@yahoo.com \\ Lima-Perú.
}

\section{Resumen}

Este artículo describe los últimos momentos de la vida de Simón Bolívar a la luz de los estudios históricos y del testimonio de primera mano del médico que asistió al Libertador, el doctor Alejandro Próspero Révérend. Asimismo, contrasta y complementa los hechos históricos con la visión de Ricardo Palma sobre los momentos finales del Libertador, descritos en su tradición "La última frase de Bolívar".

Palabras claves: Jesucristo, El Quijote, Bolívar, majaderos de la historia humana.

\begin{abstract}
Abstarct
This article describes the last moments in the life of Simón Bolivar through historical studies and the first-hand testimony of the doctor who assisted the Liberator, Dr. Alejandro Próspero Révérend. It also contrasts and complements the historical facts with Ricardo Palma's vision of the final moments of the Liberator described in his tradition "La última frase de Bolivar".
\end{abstract}

Keywords: Jesus Christ, The Quijote and Bolivvar, stubborns of human history 
José Luis Ayala Olazával (Perú): Poeta, novelista, narrador y periodista. Ha editado 60 libros y abarcado todos los géneros literarios. Escribe poesía en aymara y ha publicado varios libros así como estudios lingüísticos sobre ese idioma. Los últimos libros son: Atawallpa: Carta a los peruanos del siglo XX. Los abismos de Vargas Llosa (ensayo acerca de la evolución ideológica del Premio Nobel 2010). Desirée Lieven: mujer humanista y libertaria, etc 
Quienes conocieron y trataron de cerca al Libertador Simón Bolívar, así como la mayoría de edecanes y biógrafos que tuvieron con él una estrecha relación por diversas razones, coinciden en señalar que se trataba de un ser humano inteligente, culto, sublime, decidido, valiente, sincero y apasionado. Un rasgo sicológico particular de la personalidad del Libertador es que era además hiperactivo, término que se traduce por un mayor movimiento, permanentes acciones impulsivas y atención a varios temas a la vez. En efecto, Simón Bolívar mientras se frotaba las rodillas o caminaba, dictaba o redactaba proclamas y contestaba su correspondencia, se preocupaba especialmente por la alimentación y descanso de oficiales y soldados.

En varias tradiciones, Ricardo Palma se ha referido acerca de la singular personalidad de Simón Bolívar y ha destacado especialmente su cultura literaria como la influencia pedagógica del maestro Simón Rodríguez. Palma asevera que el destino hizo que el maestro y el discípulo se encontraran en el momento preciso en el que en América había una incontenible corriente libertadora. Sin embargo, el destino de ambos fue escrito por manos las de la deslealtad, desencanto y fatalidad. Simón Rodríguez y Bolívar murieron convencidos de que habían sido traicionados por aquellos en quienes más confiaron.

Precisamente, la tradición de Ricardo Palma titulada "La última frase de Bolívar" tiene que ver con la biografía del militar combatiente durante toda su existencia, del político genial, del gobernante apasionado y creador de cinco repúblicas: Bolivia, Colombia, Ecuador, Perú y Venezuela. Se trata de una vida dedicada a la guerra por la Independencia de América, durmiendo a la intemperie juntamente con sus soldados y oficiales, generalmente en una hamaca. Mal alimentado, desnutrido y siempre durmiendo poco debido a los avatares de las guerras, el apasionado amor y la política. 
La enfermedad y muerte de Bolívar tienen que ver, sin duda, con su sacrificada vida durante veinte años de intenso combate militar y político. Cuando llegó a Lima ya estaba enfermo y ese hecho fue duramente censurado, comentado y criticado por la aristocracia hispana limeña. Bolívar ha tenido, tuvo y tendrá muchos biógrafos, especialmente de nacionalidad venezolana. Todos coinciden en señalar su carácter indoblegable, su doctrina libertaria, su cultura política y filosófica. Masón y anticlerical supo ser, sin embargo, tolerante con un clero español adscrito a la coloniedad, sobre todo a la complicidad respecto a la esclavitud y explotación inhumana.

Desde el momento en que Bolívar pronunció el juramento: "No descansaré hasta romper las cadenas del dominio español en América", fue un compromiso que asumió en plena juventud y cumplió a costa de su enorme fortuna, patrimonio familiar, descendencia, salud y su propia vida. Desde 1812 lideró la lucha por la independencia de América, sometida por España a un permanente exterminio de sus habitantes y saqueo de sus riquezas naturales. Desde entonces su destino estuvo marcado por memorables batallas militares, triunfos, traiciones, amores, decepciones y también días felices y memorables. La vida para Bolívar fue, además, un permanente combate contra toda clase de adversidades. Hay una frase que solía repetir constantemente para autodefinirse: "Soy el hombre de las mil dificultades".

Todo empezó en 1815 cuando proclamó a Cartagena de Indias como "Ciudad heroica", por la resistencia frente al ataque de tropas españolas. En 1812 suscribió un documento fundamental llamado Manifiesto de Cartagena. Intervino en la guerra de la Independencia de Estados Unidos como en la Revolución francesa. En 1790 concibió el proyecto de la independencia de América. La idea era crear un Estadocontinente independiente con el nombre de Colombia, 
gobernado por dos presidentes llamados Incas. Secundó a Miranda y siempre lo recordó como el precursor.

En 1819 proclamó, en Angostura, la Gran Colombia y derrotó al militar español Pablo Morrillo en Bocayá. Con la victoria en Carabobo logró la independencia de Venezuela y en 1922, con el concurso de Antonio José de Sucre, liberó a Ecuador como territorio de la Gran Colombia. En 1812 fue designado generalísimo y dictador de Venezuela.

Simón Antonio de la Santísima Trinidad Bolívary Ponte Palacios y Blanco, nació el 24 de julio de 1783 en Caracas. Sus padres pertenecían a importantes linajes caraqueños: eran los "Amos del valle", criollos descendientes de los fundadores de la ciudad, pertenecientes al nivel más alto de la estructura social durante el virreinato. Cuando tenía tres años, murió su padre y a los nueve su madre. Quedó bajo el amparo de su abuelo llamado Feliciano Palacios. Fue él quien se ocupó de buscar a los mejores maestros y de dirigir la cuantiosa fortuna heredada. El maestro Simón Rodríguez fue designado como su tutor y se hizo cargo de formar su carácter, dotándolo de una cultura humanista y sobre todo de su vocación libertaria. Su abuelo murió en 1799 y fue enviado para que estudiara en Madrid. Allí se alojó en la casa del marqués de Ustáriz en la calle Atocha. Como todos los jóvenes de su clase social estudió historia, equitación, danza, lenguas extranjeras, literatura, historia universal.

En Madrid se enamoró de María Teresa del Toro (Manilo, 1965, pp. 45-56). A pesar de la oposición del padre, se casó y volvió a Venezuela para trabajar en sus haciendas, pero a los ocho meses María Teresa murió en Caracas contagiada por una desconocida fiebre. Ese hecho cambió absolutamente el curso de la vida de Bolívar. Prometió no casarse nunca más y cumplió su promesa. Luego se estableció en París, allí coincidió con su antiguo maestro Simón Rodríguez, quien lo convenció de que estudiara 
la literatura política más importante. Fue así como asimiló a Montesquieu, Rousseau, Voltaire y a otros enciclopedistas.

Convertido en militar combatiente, sus primeras batallas importantes fueron la de Boyacá y Cúcuta en 1813. Luego del Manifiesto de Cartagena, ganó gran notoriedad entre el pueblo y los militares, de modo que inmediatamente se dirigió a Caracas, desde donde realizó la llamada "Campaña Admirable". Luego sucedió la Batalla de Taguanes que se realizó en 1813. Enseguida ejecutó la toma de la ciudad de Valencia para dirigirse después a Caracas, el 3 de agosto. La batalla de Araure se realizó en diciembre de 1813, siendo parte de las denominadas "operaciones de occidente". La Batalla del Pantano de Vargas fue una de las acciones más duras y sanguinarias en Colombia por la liberación de la Nueva Granada. El ejército llegó a Tunja el 4 de agosto de 1819 y la Gran Colombia obtuvo su libertad el día 7 de agosto; fue una batalla importante debido a que pudo recuperar el ánimo de los republicanos para vencer a las tropas españolas.

La Batalla de Boyacá fue importante debido a que logró que se sellara el triunfo de la Campaña Libertadora de Nueva Granada y así terminaron los 77 días de campaña dirigida por él. Fue una derrota y un duro golpe al ejército español que empezó a perder la moral. En la Batalla de Carabobo, aunque fue muy importante porque influyó en la batalla de Boyacá, no hubo que hacer un gran esfuerzo para derrotar y expulsar a las tropas españolas de Caracas, así como del resto del territorio venezolano. En la batalla de Carabobo, que tuvo lugar en 1821, Bolívar destrozó lo que quedó del ejército español y lo expulsó de Caracas, siendo definitiva la derrota de las tropas en la posterior batalla naval del lago de Maracaibo.

La batalla de Bomboná se realizó después de la de Carabobo. Bolívar salió decidido a llegar a Pasto y Quito para sellar una 
posterior liberación del territorio que ahora es la República del Ecuador, por lo que se le llamó "La Campaña del Sur". Esta contienda fue cruenta pero venció Simón Bolívar. La batalla de Pichincha, que se realizó cerca de Quito en 1822, en las cercanías del volcán Pichincha, permitió la liberación de Quito y la proclamación de Libertador a Simón Bolívar. Quito quedó incorporado al territorio de la Gran Colombia.

Finalmente, las batallas de Junín y Ayacucho. En el año 1824, Simón Bolívar emprendió "La Campaña del Sur", para lo que se constituyó en el Perú, a fin de culminar su proyecto de largo alcance. Significó el triunfo definitivo del Libertador para obtener la independencia del Perú y la consolidación de Sudamérica. Pero Bolívar fue apartado por el general Santander, presidente de Colombia, para que no interviniera en la batalla de Ayacucho y fuera derrotado por las tropas españolas. La Batalla de Ayacucho fue un enfrentamiento con espadas y bayonetas, armamento que se usaba entonces y que decidió las guerras de independencia de América del Sur, entre 1809 y 1826. La batalla de Ayacucho se realizó en la Pampa de Quinua, en Ayacucho, el día 9 de diciembre de 1824 .

Sabido es que El Libertador no tenía ni aceptaba ningún privilegio frente a sus edecanes, oficiales y menos soldados. Comía igual que ellos y a veces disfrutaba de asado de caballos o bebidas calientes en las noches y días de lluvia. Sin embargo, los médicos que lo acompañaron le advirtieron que su salud se quebrantaba al exigir mayor esfuerzo a las tropas, cabalgando a veces durante tres días sin descanso, por lo que los soldados y oficiales le pusieron el apodo de "Culo de fierro".

Se trata entonces de veinte años de continuas batallas, viajes a lomo de caballo por caminos empinados, estepas, puentes prendidos al borde de abismos, desiertos y pampas, desfiladeros, cordilleras y quebradas. Bolívar cabalgó de Lima al Cusco, de 
allí a Puno y La Paz, y llegó a Potosí en su hermoso caballo llamado "Palomo", de quien decía que solo le faltaba hablar. Tuvo que ir de Lima a Caracas a caballo para responder a infundios y calumnias de sus enemigos gratuitos. ¿Cómo no se iba enfermar una persona que le había exigido a su cuerpo el máximo rendimiento físico? La tuberculosis tarde o temprano tenía de todas maneras que fulminarlo.

En efecto, según refiere el historiador Alejandro B. Cajal (1923, pp. 45-56), en diciembre de 1830, el repentino arribo de Simón Bolívar a Santa Marta se debió a un imprevisto cambio en el itinerario en un viaje cuyo destino era Cartagena de Indias; pero debido a un agravamiento de su estado de salud, la diligencia se vio obligada a realizar una parada en Santa Marta, para evitar empeorar su enfermedad. De modo que cambiaron los planes en referencia a futuras actividades que debía realizar. De pronto se sintió descompensado como nunca le había sucedido antes. A su llegada a Santa Marta en horas de la noche, el Libertador fue recibido de manera cordial, actitud que le generó grata impresión, debido a que había rumores de que los habitantes no le tenían simpatía. Luego de ser presentado por el general colombiano Mariano Montilla, tuvo la oportunidad de conocer a quien sería su médico de cabecera, el cirujano de guerra colombiano originario de Normandía, Francia: Alejandro Próspero Révérend. Luego de una conversación en francés con el médico, el Libertador le hizo conocer las buenas referencias que tenía de él, aunque era muy desconfiado de la medicina. El galeno era trece años menor y además responsable de su inmediata mejoría.

Pero sucedió que el pronóstico del médico no fue nada positivo, debido a que después de conversar con el Libertador acerca de su mal, le hizo notar del poco cuidado y desinterés con su enfermedad. Révérend se reunió con el doctor Mac Night, médico del barco de guerra norteamericano Grampus, que 
escoltó al Libertador en la última parte de su viaje por el río Magdalena, y ambos se pusieron de acuerdo sobre el tratamiento que se debía tener respecto a la enfermedad de Bolívar.

De inmediato el Libertador fue hospedado en la casa de aduanas, sede del consulado español construido en el centro del pueblo. Entonces, por consejos de su médico, un antiguo amigo, fiel a la causa independentista, el español nacido en Cádiz, Andalucía, Joaquín de Mier, el Libertador fue trasladado a un sitio más tranquilo, por lo que le cedió su hacienda ubicada en San Pedro de Alejandrino y, además, puso a su servicio las instalaciones, alimentación y hospedaje para toda la comitiva.

El arribo a la Quinta de San Pedro de Alejandrino fue el 6 de diciembre. Bolívar fue acomodado en una berlina tirada a caballo y el viaje tardó más debido a su estado de salud. Instalado en la Quinta de San Pedro, se puso inmediatamente en manos de su médico de cabecera, quien hizo una minuciosa observación de la evolución de su salud, expresada a través de una serie de boletines, los que aparecían después en su libro $L a$ última enfermedad, los últimos momentos y funerales de Simón Bolívar, Libertador de Colombia y del Perú, publicado en París en 1866, treinta y seis años después.

En los primeros días del tratamiento se notó un evidente optimismo del Libertador, quien empezó a hablar de planes futuros. Tenía la obsesión de que en las cercanías de la Sierra Nevada de Santa Marta, el general colombiano nacido en Navarra, España, José Sardá, construyera una cabaña en Masinga (Magdalena), y además que organizara un viaje al lado de su médico para visitar Francia. Sin embrago, el optimismo fue disminuyendo debido a su estado de salud.

Pasados algunos días, los componentes de la caravana exigieron a Alejandro Próspero Révérend que les informara acerca de la 
gravedad de la salud del Libertador para preparar los temas políticos, legales y militares y proceder adecuadamente en caso de su deceso. Hecho que ocasionó que el Libertador expresara su cólera y desagrado ilimitado. Hasta que debido a la intervención del médico, el 10 de diciembre en la noche, en presencia de los generales colombianos Mariano Montilla, José María Carreño y José Laurencio Silva, el dueño de casa, algunos amigos del Libertador y el notario Catalino Noguera, se desarrolló uno de los acontecimientos más dolorosos para Bolívar: la redacción de su testamento y el dictado de la última proclama dirigida a los colombianos. En ese documento, Simón Bolívar expresaría su visión personal de la situación política de Colombia, su soledad y tristeza, así como su pedido para que cesen las rebeliones y recordar que el proyecto es la construcción de la confederación. Este es el texto:

Colombianos: Habéis presenciado mis esfuerzos para plantear la libertad donde reinaba antes la tiranía. He trabajado con desinterés, abandonando mi fortuna y aun mi tranquilidad. Me separé del mando cuando me persuadí que desconfiabais de mi desprendimiento. Mis enemigos abusaron de vuestra credulidad y hollaron lo que me es más sagrado, mi reputación y mi amor a la libertad. He sido víctima de mis perseguidores, que me han conducido a las puertas del sepulcro. Yo los perdono.

Al desaparecer de en medio de vosotros, mi cariño me dice que debo hacer la manifestación de mis últimos deseos. No aspiro a otra gloria que a la consolidación de Colombia. Todos debéis trabajar por el bien inestimable de la Unión: los pueblos obedeciendo al actual gobierno para libertarse de la anarquía; los ministros del santuario dirigiendo sus oraciones al cielo; y los militares empleando su espada en defender las garantías sociales. 
¡Colombianos! Mis últimos votos son por la felicidad de la patria. Si mi muerte contribuye para que cesen los partidos y se consolide la Unión, yo bajaré tranquilo al sepulcro.

Simón Bolívar (En Pérez Vila, 1985, pp. 326-327)

Durante la última semana hubo un permanente movimiento y pronóstico un tanto alentador por lo que se hacían paseos cortos de campo en la Quinta de San Pedro, a fin de conseguir aire fresco. Pero en las noches el cuerpo de Bolívar no soportaba lo que el médico llamó síntomas de un catarro pulmonar crónico pero terminó en una tisis tuberculosa, por lo que el enfermo no podía dormir. Al no aceptar el tratamiento y sumado su estado de salud, resquebrajaron mucho más su débil cuerpo. El 16 de diciembre todo se agravó debido al máximo síntoma de la enfermedad, durante la mañana se presentaron cuadros terribles hasta horas de la noche, hecho que causó gran preocupación de su médico, expresado en sucesivos boletines que suscribió:

\section{BOLETÍN NÚMERO 30:}

S. E. va siempre declinando, y si vuelven las fuerzas vitales a sobresalir alguna vez, es para decaerse un rato después; finalmente, es la lucha extrema de la vida con la muerte. El vejigatorio de la nuca ha purgado bastante, pero los que se pusieron anoche en las pantorrillas han hecho muy poco efecto. Los orines se han suprimido. Siguen siempre las frotaciones espirituosas en los extremos, las bebidas antiespasmódicas, unturas emolientes y lavativas. Según cada dos horas. Diciembre 16, a la una de la tarde. 


\section{BOLETÍN NÚMERO 31 :}

Todos los síntomas de la enfermedad de S. E. han vuelto a exasperarse; además se le ha notado otro síntoma malo, y es que ha echado orines ensangrentados. La respiración es más trabajosa, y apenas han purgado los vejigatorios, principalmente los de las pantorrillas. Frotaciones espirituosas en los extremos, antiespasmódicos al interior, etc. Según por alimento. Diciembre 16, a las nueve de la noche. (Révérend, 1866, pp. 45-65)

La opinión clínica de la salud de Bolívar se aprecia con crudeza a través de los sucesivos boletines médicos suscritos por Alejandro Próspero Révérend, que fueron más seguidos desde la madrugada del 16 de diciembre y la fatal mañana del 17 de diciembre de 1830. Así es como se puede apreciar el sistemático debilitamiento de Bolívar hasta la inminente muerte en pocas horas, cuando tenía 47 años de edad.

\section{BOLETÍN NÚMERO 32:}

Todos los síntomas están llegando al último grado de intensidad; el pulso está en el mayor decaimiento; el fácies está más hipocrático que antes; en fin, la muerte está próxima. Frotaciones estimulantes, cordiales y sagú. Los vejigatorios han purgado muy poco. Diciembre 17, a las siete de la mañana. (ibíd.)

A las nueve de la mañana el médico fue requerido por el general Mariano Montilla respecto al estado de salud del Libertador. El médico respondió que el pronóstico era grave y lo que había que hacer era preparar los funerales. Luego de realizar un examen respecto al estado de Bolívar, se presentó un cuadro desalentador muy grave. El Libertador hablaba de modo incoherente, lo que convenció a todos que se trataba de las últimas horas de vida. 
La mañana fue plagada de desvanecimientos y pérdida de reacciones vitales. Luego del mediodía, un silencio mortal inundó el elegante salón de la casa hacienda, donde se encontraban edecanes, el mando militar y amigos más cercanos del Libertador. De pronto irrumpió el médico Alejandro Próspero Révérend y los invitó a constituirse en la habitación para presenciar la muerte de Simón Bolívar. Después de una larga y calmada agonía, murió a la una de la tarde con tres minutos y cincuenta y cinco segundos del viernes 17 de diciembre de 1830 .

Ricardo Palma, en la tradición "La última frase de Bolívar", narra la muerte del Libertador de la siguiente manera:

La escena pasa por la hacienda San Pedro de Alejandrino, y en una tarde de diciembre del año 1830.

En el espacioso corredor de la casa, y sentado en un sillón de baqueta, veíase a un hombre demacrado, a quien una voz cavernosa y tenaz convulsionaba de hora en hora.

El médico, un sabio europeo, le propinaba una poción calmante, y dos viejos militares, que silenciosos y tristes paseaban en el salón, acudían solícitos al corredor.

Más que un enfermo se trataba ya de un moribundo, pero de un moribundo de inmortal renombre.

Pasado un fuerte acceso, el enfermo se sumergió en profunda meditación, y al cabo de algunos minutos dijo con voz muy débil.

- ¿Sabe usted, doctor, lo que me atormenta al sentirme ya próximo a la tumba?

-No, mi general.

- La idea de que tal vez haya edificado sobre arena movediza y arado en el mar. 
Y un suspiro brotó de lo más íntimo de su alma y volvió a hundirse en su meditación.

Transcurrido un gran rato, una sonrisa tristísima se dibujó en un rostro y dijo pausadamente.

- ¿No sospecha usted, doctor, quiénes han sido los tres más insignes majaderos del mundo?

-Ciertamente que no, mi general.

-Acérquese usted, doctor, se lo diré al oído.

-Los tres grandísimos majaderos hemos sido Jesucristo, Don Quijote y yo. (1974, p. 34)

Después del deceso del Libertador se desarrolló el protocolo médico para determinar la causa de su muerte y se realizó la autopsia; luego se procedió al embalsamiento y traslado de los restos mortales para exponerlos en la capilla del poblado. A los tres días se realizó el entierro en una tumba prestada por la familia Díaz Granados ubicada en la catedral basílica de Santa Marta. La autopsia del Libertador se realizó en una de las salas conjuntas de la Quinta de San Pedro Alejandrino, por lo que el médico llegó a la conclusión aparecida en sus memorias:

Según este examen, es fácil reconocer que la enfermedad que ha muerto S. E. el Libertador era en un principio un catarro pulmonar, que habiendo sido descuidado pasó al estado crónico y consecutivamente degeneró en tisis tuberculosa. (1866, p.)

¿Qué es un majadero? Significa que una persona se comporta con necedad y falta de sensatez. El término majadero se aplica, a la persona que tiene poco juicio o se comporta de manera imprudente. Sin embargo, Simón Bolívar nunca tuvo nada de loco, insistente e imprudente. Mucho menos Jesucristo ni el Quijote. Majadero, en este caso, significa exigente, lúcido y apasionado. 
Simón Bolívar, en sus últimos días, entendió que su sueño de ver unidos en una gran nación a los pueblos liberados era solo un sueño. Esa gran nación fue destruida sin haber nacido ni menos construida, todo por culpa de insensatos de visión corta y no de un águila que avizora el horizonte, como sí lo hizo Bolívar. Al considerarse un majadero, hacía ver a los que lo traicionaron que su obra se comparaba a la de Jesucristo, aquel hombre que fue capaz de dividir al mundo y a la historia de la humanidad (Viños, 1980, pp. 38-43). Por su lado, el Quijote, producto del genio de Cervantes, fue un loco que se inmortalizó en la historia de la literatura como el caballero andante; se enfrentó a unos molinos de viento como si fueran monstruos que quisieran devorar el sueño de Dulcinea.

Bolívar y Jesús fueron visionarios, soñadores, negados y traicionados por sus más allegados. Bolívar, por Santander y Páez; Jesús, por Judas y Pedro. Quizás el personaje del manco de Lepanto, el Quijote, no tuvo esa suerte fatal; sin embargo, fue un empecinado romántico duramente golpeado por defender la justicia, el honor, el amor y la amistad. Cristo, el otro majadero, traicionado y juzgado sin abogado defensor y por jueces parcializados, lo condenaron en un juicio de pocas horas que lo llevó a la crucifixión, todo por defender la verdad, el amor entre hermanos, el perdón, la solidaridad y la justicia.

Los tres majaderos, a los que hace alusión Bolívar, tuvieron mucho en común en todo aquello que hicieron por el prójimo. Bolívar por la libertad, las repúblicas y la unión de los pueblos. No obstante, aró en el mar. Jesús murió por la verdad y el amor entre hermanos. Bolívar consideró al Quijote como un majadero por haber defendido el honor, la verdad y la justicia. 


\section{Bibliografía}

Cajal B., A. (1923). Simón Bolívar, una vida al servicio de la libertad. Quito: Editora Cumbre.

Manilo, B. (1965). Las batallas decisivas políticas y militares de Simón Bolivar. Barquisimeto: Edición pedagógica.

Pastor, A. (1934). La persistente tos de Bolivar: Caracas: Ediciones Cumbre.

Palma, R. (1974). Tradiciones peruanas. Lima: Empresa Editora Andina S. A.

Pérez Vila, M. (ed.). (1985). Doctrina del Libertador. Biblioteca Ayacucho, Volumen 1 Documento No. 100, pp. 326-327. Caracas: Venegraf.

Fundación Polar, ed. (1997). Diccionario de Historia de Venezuela. Segunda edición. Caracas: Fundación Empresas Polar.

Révérend, A. P. (1866). La última enfermedad, los últimos momentos y los funerales de Simón Bolivar, Libertador de Colombia y del Perú. París: Imprenta Hispano-Americana de Cosson y Comp.

Tapia Gutiérrez, P. (1987). ¿De qué murió Bolívar? Santa Fe: Editorial Libre.

Viños, E. (1980). El majadero Bolívar y el Dr. Reverend. "Boletines de la muerte": p.p. 28-39. Caracas: Editora Santa Fe.

Recibido el 17 de octubre de 2019 Aceptado el 14 de noviembre de 2019 